\title{
ARTICLES ORIGINAUX
}

\section{Sur l'emploi d'un vaccin antirabique formolé à usage vétérinaire en Afrique-Occidentale française}

\author{
par G. LEFROU et J. MARTIGNOLES
}

\begin{abstract}
En Algérie, où la vaccination antirabique préventive des chiens est employée sur une vaste échelle, après avoir fait l'objet d'une réglementation officielle (Décret présidentiel du 19 août 1936), l'Institut Pasteur d'Alger a cru devoir préparer deux vaccins antirabiques différents, l'un phéniqué pour les hommes, l'autre formolé pour les chiens.

La question de l'efficacité respective de ces deux vaccins étant hors de cause, l'Institut Pasteur d'Alger donne les raisons suivantes justifiant l'emploi d'un vaccin formolé spécial à l'usage vétérinaire :

$1^{\circ}$ Le vaccin formolé ne contenant pas de virus vivant (1) ne peut en aucun cas donner une rage de laboratoire, ce qui est essentiel lorsqu'il s'agit d'une vaccination s'adressant aux chiens.

$2^{\circ}$ Le vaccin formolé est d'une conservation beaucoup plus facile que le vaccin phéniqué (2) : placé dans un endroit frais et à l'abri de la lumière, le
\end{abstract}

(1) Dans le vaccin phéniqué, le virus est présent à un stade intermédiaire entre le virus vivant et le virus mort inactif.

Une récente expérimentation de $A$. Queseda et Altieri, rapportée dans le B. I. P., août 1953, précise bien les propriétés particulières du vaccin phéniqué de Fermi :

a) Le vaccin de Fermi à $1 \%$, deux jours après sa préparation, inoculé par voie sous-cutanée à 20 chiens a déterminé la rage chez un chiot sans rendre virulent l'encéphale; $b$ ) ce vaccin, inoculé par voie intra-rachidienne immédiatement après sa préparation et 2 jours après, provoque la rage de sept chiens sur huit ; c) le même vaccin, après 8 à 12 jours de préparation, est inoffensif pour 12 chiens; d) ce même vaccin ne provoque pas la rage après inoculation intra-rachidienne si sa préparation remonte de 28 à 90 jours.

(2) Le vaccin phéniqué, après 24 heures d'atténuation à $+25^{\circ} \mathrm{C}$ doit être conservé à une température ne dépassant pas $+5^{\circ}$, et il est utilisable seulement pendant une période de 3 mois. vaccin conserve ses propriétés immunisantes pendant au moins deux ans : placé de $+20^{\circ}$ à $+30^{\circ} \mathrm{C}$, suivant l'expérimentation faite par Jacotot, il est encore actif au bout d'un an.

Cette stabilité du vaccin facilite une large diffusion pour l'usage vétérinaire, puisqu'il n'y a pas besoin de le garder en réfrigérateur et d'organiser des centres spéciaux de vaccination, destinés à recevoir le vaccin des Instituts Vaccinogènes dans de bonnes conditions de conservation pendant le 'transport.

Prenant comme base ce qui existe en Algérie, nous avons pensé que l'A. $O$. F., où la rage, connue sous le nom de "Oulou Fato " (Chien Fou), est aussi très fréquente, avait le même intérêt, pour les mêmes raisons, à avoir aussi à sa disposition deux vaccins antirabiques, l'un pour les hommes, préparé à Dakar par l'Institut Pasteur d'A. O. F., l'autre pour les animaux, préparé par l'Institut Pasteur de Kindia.

Ce vaccin formolé a été préparé à l'Institut Pasteur de Kindia suivant la technique générale indiquée par Plantureux qui a été le promoteur de $\mathrm{Ce}$ vaccin antirabique (Arch. I. P., Algérie, 1926, 1927, 1928).

Mais, comme du fait de certaines contirigences, nous avons été amenés à modifier la technique de Plantureux, nous pensons qu'il y a intérêt à faire connaître ce qui a été acquis à ce sujet, d'où le présent mémoire.

L'expérimentation concernant le vaccin a porté sur 30 chiens et sur 60 singes (cynocéphales).

Comme suite aux résultats des épreuves d'efficacité qui ont été pratiquées, une décision en date du 23 septembre 1952, du Haut Commissaire de la République Gouverneur Général de l'A. O.F., a alors autorisé la mise en circulation de ce vaccin antirabique, en modifiant les paragraphes 1 et 3 de la Circulaire du 14 août 1940 sur la vaccination antirabique préventive des chiens en A. O.F. : Les vaccins employés seront le vaccin phéniqué préparé par l'Institut Pasteur de Dakar ou le Laboratoire de l'Élevage de Dakar et le vaccin formolé préparé par l'Institut Pasteur de Kindia. 
Au cours de l'année 1953, il a ainsi été fourni aux divers Services de l'Élevage du Territoire de l'A. O. F. 3.214 ampoules de $10 \mathrm{~cm}^{3}$, ce qui correspond à la vaccination de 800 chicns.

\section{CONDITIONS GÉNÉRALES DE PRÉPARATION}

\section{A) Virus fixe rabique.}

A l'Institut Pasteur d'Alger, le virus employé est le virus fixe Pasteur Tanger.

A l'Institut Pasteur de Kindia, le virus utilisé provient d'une souche de virus de rue, isolé à Pastoria en octobre 1949, à partir d'un chien de race indigène atteint de la rage africaine, appelée en A. O. F. "Oulou Fato ».

Cette souche en est actuellement à son $61 \mathrm{e}$ passage sur lapin; la période d'incubation a varié de 22 jours à 9 jours. A partir du $15^{\mathrm{e}}$ passage, la mort, après paralysie, est survenue du $11^{\mathrm{e}}$ au $9^{\mathrm{e}}$ jour ; le virus a présenté les caractères du virus fixe. Le taux de virulence a été recherché sur 6 cynocéphales (animal facile à se procurer à Pastoria), par voie intra-cérébrale.

La dilution d'émulsion s'est montrée virulente à des taux allant jusqu'à 1 pour 1.000 .000 ; ce virus est donc très actif.

Par ailleurs, il s'agit d'un virus peu éloigné de son origine canine, ce qui est d'une importance indubitable, suivant les notions exposées par Remlinger, d'autant plus à prendre en considération lorsqu'il est pratiqué des vaccinations canines.

En fait, les épreuves sur les chiens et les cynocéphales ont prouvé que cette souche avait un pouvoir antigénique élevé.

La souche Pasteur Tanger utilisée à l'Institut Pasteur de Dakar pour la préparation du vaccin phéniqué en était, en 1951, à son $1.005^{\mathrm{e}}$ passage.

\section{B) Préparation de l'émulsion.}

A l'Institut Pasteur d'Alger, suivant la technique de Plantureux, le cerveau rabique, broyé au Latapie, est émulsionné dans 10 parties d'eau physiologique formolée à 6 pour 1.000 (Plantureux: a d'abord utilisé une dilution à 4 pour 1.000); on passe ensuite sur de la gaze et on laisse le mélange à $+10 \%+15^{\circ} \mathrm{C}$ pendant une semaine. Après centrifugation, le culot est dilué dans huit parties d'eau physiologique et ce mélange, réparti en ampoules, constitue le vaccin antirabique formolé. Il est employé après avoir été conservé deux mois à la température de 6 à $10^{\circ}$.

A l'Institut Pasteur de Kindia, on emploie comme broyeur, non le Latapie mais un appareil nouveau, appelé "Tunnix », qui donne une émulsion extrêmement fine, supprimant la nécessité de passer sur gaze.

Par ailleurs, d'après les travaux de Jacotot à
I'Institut Pasteur de Nha-Trang, en Indochine (I. P., 1938), il apparaît que l'élimination du formol, puis le lavage à l'eau physiologique, peuvent très bien être supprimés. Le formol, en effet, maintenu en contact avec la substance nerveuse, permet au vaccin de conserver encore son pouvoir immunisant pendant 14 mois à la tempéralure de 20 à $30^{\circ}$.

La question qui se posait alors, était de savoir si une émulsion formolée à 6 pour 1.000 pouvait être injectée sans provoquer une réaction cutanée, due à l'irritation par le formol. Les expérimentations, faites à ce sujet (voir le chapitre innocuité) ont montré que le vaccin formolé ne donnait aucune réaction; chez les chiens. Dans ces conditions, il apparaît beaucoup plus simple de ne pas éliminer le formol, ce qui a l'avantage, dans une certaine mesure, d'arrêter le développement des souillures bactériennes et d'éviter aussi les accidents d'infection.

Ainsi, pour divers lots, l'ensemencement sur gélose a donné 0 à 8 colonies pour $1 \mathrm{~cm}^{3}$ de vaccin.

Un vaccin ainsi préparé, au taux de 6 pour 1.000 , a été expérimenté sur une série de 15 chiens et 16 cynocéphales, en pratiquant 3 injections souscutanées ou intra-musculaires (voir paragraphe suivant).

Ensuite, dans le but de réduire le nombre d'injections de trois à deux, l'émulsion a été concentrée au $1 / 6$ et le taux de formol, pour diminuer les effets irritants, a été abaissé à 4 pour 1.000 .

Cette modification était d'ailleurs conforme à l'exposé sur l'amélioration des types de vaccin antirabique qui a été fait à la première session du Comité d'Experts de la Rage de l'Organisation Mondiale de la Santé (Genève, avril 1950) : Il a été dit : «On a pu mettre en évidence qu'un titre élevé de la suspension de substance cérébrale initiale, une plus forte concentration de l'émulsion des tissus, une plus faible concentration des substances chimiques inactivantes, une connaissance plus précise du temps nécéssaire pour inactiver le virus et de la température: pendant le processus d'inactivation permettent $d$ 'améliorer les propriétés immunisantes de certains vaccins, " L'experimentation a alors été entreprise avec cette nouvelle préparation (voir paragraphe suivant).

A titre documentaire, mentionnons que le vaccin antirabique utilisé aux Etats-Unis est constitué par une émulsion de $20 \%$ de substances cérébrales (Stazz et Stafford, analysé in B. I. P., avril 1952, p. 369). Par ailleurs, le vaccin phéniqué, préparé suivant la méthode de Fermi, ne contient que $5 \%$ de substance cérébrale, et il est phéniqué à l $1 \%$ : ainsi l'émulsion du vaccin phéniqué est à peu près trois fois moins concentrée que l'émulsion du vaccin formolé. 


\section{C) Emploi du singe comme fournisseur du virus .}

A Alger, les émulsions constituant le virus antirabique sont préparées avec des cerveaux de chien, animal dont l'encéphale est beaucoup plus volumineux que celui du lapin, et permet ainsi d'avoir d'un seul coup une grande quantité de vaccin.

A Dakar, pour la préparation du vaccin antirabique phéniqué, on se sert pour les mêmes raisons du cerveau du mouton.

A Pastoria, il existe un autre animal facile à se procurer, c'est le cynocéphale (Papio papio), c'est alors celui-ci qui est employé comme fournisseur de virus rabique passé de lapin à singe.

Pour des cynocéphales pesant de 12 à $1 \mathrm{~kg} 800$, suivant l'âge, le poids du cerveau varie de 170 à 120 grammes. Il est intéressant de rappeler que, chez l'homme, le poids du cerveau croit de façon régulière jusqu'à 7 ans, et, à partir de cet âye, il n'est pas loin de son poids définitif qu'il atteint par progression lente a 15 ans.

Ceci pour montrer que le poids de l'encéphale ne varie pas proportionnellement au poids somatique du cynocéphale.

Seuls, les encéphales du premier passage lapinsinge sont utilisés, car, il est connu, d'après les propres travaux de Pasteur, que le passage de singe à singe affaiblit le virus rabique, au point qu'après plusieurs passages, le virus peut être définitivement atténué lorsqu'il est rapporté sur le chien.

Pasteur avait même eu l'idée d'utiliser cette méthode d'atténuation pour faire des essais de vaccination, qui, dans la suite, ont été abandonnés. Mais beaucoup plus tard, cette technique vaccinale particulière a été mise au point et, actuellement, aux Indes Néerlandaises, on utilise un vaccin antirabique formolé, préparé avec un virus fixé sur des singes (1).

Pour le moment, à Pastoria, il ne peut être question d'utiliser un virus fixe de lapin. passé de singe à singe. Mais l'expérimentation est en cours pour avoir un virus fixe de singe et en étudier ensuite le comportement.

\section{EXPÉRIMENTATION SUR LA RAGE}

Comme préambule, il est d'un grand intérêt de signaler d'abord que le vaccin formolé ne contenant que du virus tué ne peut jamais donner une rage

(1) Il paraît intéressant de faire remarquer que, d'après l'expérimentation faite dans les Indes Néerlandaises, on n'observerait pas de paralysie au cours des vaccinations antirabiques pratiquées avec une émulsion de cerveau de singe. dite de laboratoire, ce qui est essentiel lorsqu'il s'agit d'une vaccination s'adressant à des chiens.

Lapins. - 2 lapins ont reçu sous la duremère, $0 \mathrm{~cm}^{3} 25$ de ce vaccin formolé. Pendant une période d'observation d'un mois, aucun n'a présenté de troubles pathologiques.

Chiens. - A Pastoria même, 25 chiens ont reçu deux à trois injections sous-cutanées de $20 \mathrm{~cm}^{3}$ de vaccin formolé à 8 à 10 jours d'intervalle. Il n'y a eu aucune réaction cutanée locale.

Cynocéphales. - 8 cynocéphales du poids moyen de 2,5 à 3 kilos ont reçu 3 injections souscutanées de $10 \mathrm{~cm}^{3}$ de vaccin formolé à 10 jours d'intervalle.

Ces 8 singes ont prèsenté après la $2^{e}$ ir.jection, et au niveau de celle-ci, une plaie circulaire anfractueuse de la grandeur d'une pièce de monnaie. Aucune réaction ne s'est présentée après la troisième injection. En fait, ces cynocéphales ont eu une réaction cutanée locale, bien connue en physiologie sous le nom de "phénumène d'Arthus ». C'est une réaction anaphylactique qui se produit chez certains animaux après des injections répétées de substances protéiques.

Cet accident cutané, qui a lieu facilement chez le lapin après des injections répétées de sérum de cheval faites à au moins 7 jours d'intervalle, n'a jamais pu être provoqué chez le chien. Aussi, c'est cet animal qui dans les laboratoires de physiologie, est toujours utilisé pour étudier les phénomènes généraux de l'anaphylaxie.

Il est d'ailleurs utile de faire remarquer que, d'après les travaux d'Arthus, ces lésions locales n'empêchent nullement l'immunité de se produire, lorsqu'il s'agit d'injections répétées d'un produit biologique. Il y a lieu d'attirer aussi l'attention sur le fait que, chez le lapin, le phénomène d'Arthus ne se produit généralement qu'après la quatrième injection sous-cutanee, alors que chez le cynocéphale, il y a une réaction dès la deuxième injection.

Après une première série d'expérimentations, le vaccin a été utilisé en injections intra-musculaires; il n'y a plus eu de réaction.

Ceci correspond aux faits observés par Arthus chez les lapins : quand on injecte le sérum dans les muscles, les accidents se produisent un peu plus tard qu'avec des injections sous-cutanées.

\section{RÉSUME MÉTHODIQUE}

\section{Première série d'expéximentations.}

Emulsion au 1/10.

Taux de formol: 6 pour 1.000 .

Vaccination avant contamination.

Voies sous-cutanée et intra-musculaire. 


\section{I. - Chiens (17)}

\section{4 chiens vaccinés :}

2 injections ( $\mathrm{s} / \mathrm{c}), 20 \mathrm{~cm}^{3}$, intervalle 20 jours. Inoculation intra-oculaire 35 jours après la $2^{\mathrm{e}}$ injection,

1 mort le $16^{\ominus}$ jour après l'inoculation.

$1-18^{\mathrm{e}}$

$$
\text { TOTAL }\left\{\begin{array}{l}
2 \text { MORTS } \\
2 \text { SURVIVANTS }
\end{array}\right.
$$

6 chiens vaccinés :

2 injections $(\mathrm{s} / \mathrm{c}), 20 \mathrm{~cm}^{3}$, intervalle 20 jours. Inoculation intra-oculaire 50 jours, après la $2^{e}$ injection,

1 mort le $14^{\mathrm{e}}$ jour après l'inoculation.

$$
\begin{aligned}
& 1-17^{\mathrm{e}} \\
& 1-21^{\mathrm{e}} \\
& 1-22^{\mathrm{e}} \\
& \text { TOTAL }\left\{\begin{array}{l}
4 \text { MORTS } \\
2 \text { SURVIVANTS }
\end{array}\right.
\end{aligned}
$$

\section{5 chiens vaccinés :}

3 injections $(\mathrm{s} / \mathrm{c}), 20 \mathrm{~cm}^{3}$, intervalle 10 jours. Inoculation intra-musculaire 30 jours après la $2^{e}$ injection,

1 mort le $14^{\mathrm{e}}$ jour après l'inoculation.

$1-20^{\mathrm{e}}$

$$
\text { TOTAL }\left\{\begin{array}{l}
2 \text { MORTS } \\
3 \text { SURVIVANTS }
\end{array}\right.
$$

\section{2 chiens témoins :}

Inoculation intra-oculaire,

1 mort le $14^{\mathrm{e}}$ jour après l'inoculation.

$$
1-15^{\mathrm{e}} \frac{-}{2 \text { MORTS }}
$$

\section{II. - Cynocéphales (21).}

\section{7 cynocéphales vaccinés :}

3 injections $(\mathrm{s} / \mathrm{c}), 10 \mathrm{~cm}^{3}$, intervalle 10 jours. lre inoculation intra-musculaire (masseter) le $24^{\circ}$ jour après la $3^{\mathrm{e}}$ injection,

1 mort le $13^{\mathrm{e}}$ jour après l'inoculation.

$1-13^{\mathrm{e}}$

$2^{e}$ inoculation intra-musculaire (nuque) le $30^{\mathrm{e}}$ jour après la lre inoculation,

I mort le $19^{\mathrm{e}}$ jour après l'inoculation.

$$
\begin{aligned}
& 1-30^{\circ} \\
& 1-42^{\circ} \\
& 1-48 \mathrm{e} \\
& 1-49 \mathrm{e} \\
& \text { TOTAL }\left\{\begin{array}{l}
7 \text { MORTS } \\
\text { ZERO SURVIVANT }
\end{array}\right.
\end{aligned}
$$

9 cynocéphales vaccinés :

3 injections (i/m), $20 \mathrm{~cm}^{3}$, intervalle 7 jours.

$1^{\text {re }}$ inoculation intra-musculaire le $30^{\mathrm{e}}$ jour après la $3^{e}$ injection,

1 mort le $42^{\mathrm{e}}$ jour (maladie intercurrente).

$2^{\theta}$ inoculation intra-oculaire le $45^{\theta}$ jour après la Ire inoculation,

TOTAL $\left\{\begin{array}{l}\text { I MORT DE MALADIE INTERCURRENTE } \\ \text { ZERO MORT DE RAGE } \\ 8 \text { SURVIVANTS }\end{array}\right.$

5 cynocéphales témoins :

$1^{\text {re }}$ inoculation intra-musculaire,

1 mort le $18^{e}$ jour après l'inoculation.

$1-24 \mathrm{e}$

$2^{\mathrm{e}}$ inoculation intra-musculaire le $26^{\mathrm{e}}$ jour après la $1^{\text {re }}$ inoculation,

1 mort le $29^{\mathrm{e}}$ jour après l'inoculation.

$$
1-{ }_{\text {TOTAL }}^{35^{\circ}}\left\{\begin{array}{l}
4 \text { MORTS } \\
1 \text { SURVIVANT }
\end{array}\right.
$$

\section{Deuxième série d'expérimentations}

Emulsion au $1 / 6$.

Taux de formol : 4 pour 1.000 .

Vaccination avant contamination.

Voies sous-cutanée et intra-musculaire.

\section{I. - Chiens (10).}

10 chiens vaccinés :

2 injections $(\mathrm{i} / \mathrm{m}), 20 \mathrm{~cm}^{3}$, intervalle 7 jours.

1 mort le $3^{e}$ jour après l'inoculation. (maladie intercurrente.)

TOTAL $\left\{\begin{array}{l}\text { I MORT DE MALADIE INTERCURRENTE } \\ \text { ZERO MORT DE RAGE } \\ 9 \text { SURVIVANTS }\end{array}\right.$

3 chiens témoins :

Inoculation $(\mathrm{i} / \mathrm{m})$.

1 mort le $12^{e}$ jour après l'inoculation.

$1-22^{\mathrm{e}}$

$$
\text { TOTAL } \begin{cases}2 & \text { MORTS } \\ 1 & \text { SURVIVINT }\end{cases}
$$

\section{II. - Cynocéphales (24).}

\section{9 cynocéphales vaccinés :}

2 injections (s/c), $20 \mathrm{~cm}^{3}$, intervalle 7 jours.

Inoculation intra-musculaire le $16^{e}$ jour après la $2^{e}$ injection,

1 mort le $10^{\mathrm{e}}$ jour après l'inoculation.

$$
\begin{aligned}
& 1-10^{\circ} \\
& 1-23^{\mathrm{e}} \\
& 1-27^{\mathrm{e}} \\
& \text { TOTAL }\left\{\begin{array}{l}
4 \text { MORTS } \\
5 . \text { SURVIVANTS }
\end{array}\right.
\end{aligned}
$$




\section{0 cynocéphales vaccinés :}

2 injections $(\mathrm{i} / \mathrm{m}), 20 \mathrm{~cm}^{3}$, intervalle 7 jours.

$\mathrm{l}^{\text {re }}$ inoculation intra-musculaire 6 jours après la

$2^{\mathrm{e}}$ injection,

10 survivants le $42^{e}$ jour après l'inoculation.

$2^{\mathrm{e}}$ inoculation intra-oculaire 42 jours après la

$l^{\text {re }}$ inoculation,

1 mort le $54^{\mathrm{e}}$ jour après l'inoculation.

$$
\text { TOTAL } \begin{cases}1 & \text { MORT } \\ 9 & \text { SURVIVANTS }\end{cases}
$$

\section{4 cynocéphales et 1 callitriche vaccinés :}

5 injections $(\mathrm{i} / \mathrm{m}), 20 \mathrm{~cm}^{3}$, intervalle 7 jours.

Inoculation intra-cérébrale (émulsion à l \%) le

4 e jour apres la $5^{e}$ injection,

1 mort le $18^{\mathbf{e}}$ jour après l'inoculation.

TOTAL $\left\{\begin{array}{l}1 \text { MORT } \\ 4 \text { SURVIVANTS }\end{array}\right.$

TABLEAU SYNOPTIQUE

\begin{tabular}{|c|c|c|c|c|}
\hline \multicolumn{5}{|c|}{$\begin{array}{l}\text { Vaccination préventive avant contamination. } \\
\text { Vaccination suivie d'inoculation. }\end{array}$} \\
\hline ESPËCES & VACCINÉS & INOCULES & VIVANTS & VIVANTS \\
\hline $\begin{array}{r}\text { CHIENS }(30) \\
2 \text { injections } A(\mathrm{~s} / \mathrm{c}), 20 \mathrm{~cm}^{8} \text {, intervalle } 20 \text { jours } \ldots \ldots \ldots \\
3 \text { injections } A(\mathrm{~s} / \mathrm{c}), 20 \mathrm{~cm}^{3} \text {, intervalle } 10 \text { jours } \ldots \ldots \ldots \\
2 \text { injections } B(\mathrm{i} / \mathrm{m}), 20 \mathrm{~cm}^{3} \text {, intervalle } 7 \text { jours } \ldots \ldots \ldots \\
\text { Témoins : Inoculés pour } A \ldots \ldots \ldots \ldots \ldots \ldots \ldots \\
\text { Inoculés pour } B \ldots \ldots \ldots \ldots \ldots \ldots\end{array}$ & $\begin{array}{r}10 \\
5 \\
10\end{array}$ & $\begin{array}{r}10(\mathrm{i} / \mathrm{o}) \\
5(\mathrm{i} / \mathrm{m}) \\
10(\mathrm{i} / \mathrm{m}) \\
2(\mathrm{i} / \mathrm{o}) \\
3(\mathrm{i} / \mathrm{m})\end{array}$ & $\begin{array}{l}4 \\
3 \\
9 \\
0 \\
1\end{array}$ & $\begin{array}{r}40 \% \\
60 \% \\
90 \% \\
0 \% \\
33 \%\end{array}$ \\
\hline 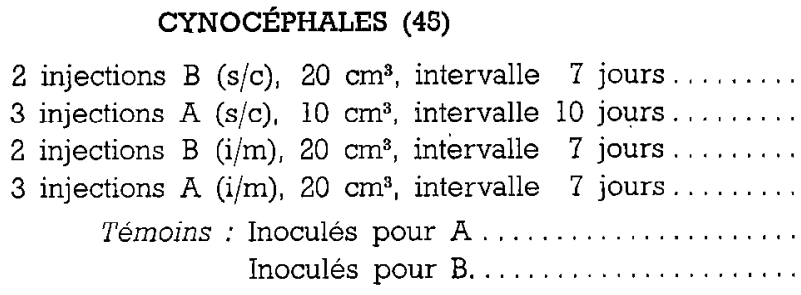 & $\begin{array}{r}9 \\
7 \\
10 \\
9\end{array}$ & $\begin{array}{c}9(\mathrm{i} / \mathrm{m}) \\
7(\mathrm{i} / \mathrm{m}) \\
10(\mathrm{i} / \mathrm{o}) \\
9(\mathrm{i} / \mathrm{o}) \\
5(\mathrm{i} / \mathrm{m}) \\
5(\mathrm{i} / \mathrm{m})\end{array}$ & $\begin{array}{l}5 \\
0 \\
9 \\
8 \\
1 \\
0\end{array}$ & $\begin{array}{r}55 \% \\
0 \% \\
90 \% \\
88 \% \\
20 \% \\
0 \%\end{array}$ \\
\hline \multicolumn{5}{|c|}{$\begin{array}{l}\text { Vaccination préventive après contamination. } \\
\text { Inoculation suivie de vaccination. }\end{array}$} \\
\hline ESPËCES & VACCINÉS & INOCULÉS & VIVANTS & VIVANTS \\
\hline $\begin{array}{l}\text { CYNOCÉPHALES }(9) \\
2 \text { injections } A(\mathrm{i} / \mathrm{m}), 20 \mathrm{~cm}^{3} \text {, intervalle } 2 \text { jours } \ldots \ldots \ldots \\
2 \text { injections } B(\mathrm{i} / \mathrm{m}), 20 \mathrm{~cm}^{3} \text {, intervalle } 7 \text { jours........ } \\
\text { injection faite } 2 \text { et } 7 \text { jours après inoculation : } \\
\text { Témoins : }\end{array}$ & $\begin{array}{l}2 \\
5\end{array}$ & $\begin{array}{l}2(\mathrm{i} / \mathrm{m}) \\
5(\mathrm{i} / \mathrm{m}) \\
2(\mathrm{i} / \mathrm{m})\end{array}$ & $\begin{array}{l}2 \\
4 \\
0\end{array}$ & $\begin{array}{r}100 \% \\
80 \% \\
0 \%\end{array}$ \\
\hline $\begin{array}{l}\text { NOTA : Injection } A \text { avec émulsion au } 1 / 10 \text {. } \\
\text { Injection } B \text { avec émulsion au } 1 / 6 \text {. }\end{array}$ & & & . & $\vdots$ \\
\hline
\end{tabular}


5 cynocéphales témoins :

Inoculation intra-oculaire,

$$
\begin{aligned}
& 1 \text { mort le } 10^{e} \text { jour après l'inoculation. } \\
& 1-25 \mathrm{e} \\
& 1-34^{\mathrm{e}} \\
& 1-39^{\circ} \\
& 1-45^{\mathrm{e}} \text {. } \\
& \text { TOTAL }\left\{\begin{array}{l}
5 \text { MORTS } \\
\text { ZERO SURVIVANT }
\end{array}\right.
\end{aligned}
$$

Troisième série d'expérimentations.

Vaccination après contamination.

\section{Cynocéphales :}

2 cynocéphales inoculés et traités.

Inoculation $(\mathrm{i} / \mathrm{m})$.

2 injections (émulsion $\AA$ ) intra-musculaires, $20 \mathrm{~cm}^{3}$, intervalle 2 jours à partir du $2^{\mathrm{e}}$ jour,

TOTAL 2 SURVIVANTS

2 cynocéphales inoculés témoins : Inoculation $(\mathrm{i} / \mathrm{m})$,

I mort le $19 \mathrm{e}$ jour après l'inoculation.

$1 \ldots 31 \mathrm{e}$

TOTAL $\left\{\begin{array}{l}2 \text { MORTS } \\ \text { ZERO SURVIVANT }\end{array}\right.$

5 cynocéphales inoculés et traités :

Inoculation $(\mathrm{i} / \mathrm{m})$.

2 injections (émulsion B) intra-musculaires, $20 \mathrm{~cm}^{3}$, intervalle 7 jours à partir du $2^{\mathrm{e}}$ jour,

1 mort le $7^{\mathrm{e}}$ jour apròs l'inoculation.

$$
\text { TOTAL } \begin{cases}1 & \text { MORT } \\ 4 & \text { SURVIVANTS }\end{cases}
$$

\section{COMMENTAIRES SUR LES CONTROLES D 'EFFICACITÉ}

\section{I. - Souche du virus.}

Le virus utilisé pour éprouver les animaux vaccinés a été le virus fixe isolé à l'Institut Pasteur de Kindia.

Il s'agit d'un virus très virulent par inoculation intra-cérébrale, puisque la dilution d'émulsion s'est montrée capable de donner la rage jusqu'au taux. de un millionième.

Mais il est nécessaire de savoir que la virulence des virus fixes varie avec l'augmentation du nombre de passages par le cerveau; ainsi, elle s'exalte de plus en plus pour le systeme nerveux central, alors qu'elle s'atténue au contraire pour les autres tissus. Le virus de rue isolé par Pasteur, qui en est dans les divers Instituts à plus de 1.000 passages, a un pouvoir infectant ne se manifestant plus par injections souscutanées; par contre, l'inoculation intra-oculaire donne toujours des résultats. Il faut ajouter que, suivant la notion classique, le virus fixe ne donne que des rages paralytiques; de fait, tous les chiens et singes inocules à Pastoria ont fait sans exception de la rage paralytique. Le virus de l'Institut Pasteur de Kindia qui est encore peu éloigné de sa souche canine est actuellement encore virulent par voie intra-musculaire : sur 7 cynocéphales inoculés, il y a eu 6 morts.

\section{II. - Voie d'inoculation du virus.}

a) INOCULATION SOUS-CUTANÉE.

L'inoculation sous-cutanée se montre très infidèle pour transmettre la rage (elle échoue même généralement si l'on fait appel à un virus fixe très adapté au tissu nerveux).

\section{b) INOCULATION INTRA-MUSCULAIRE.}

Pour expérimenter la valeur des vaccins, c'est la méthode de choix car elle correspond à ce qui se passe dans les conditions habituelles des morsures. Comme lieu d'inoculation, on peut utiliser les muscles cruraux, les muscles de la nuque, le masseter.

L'inoculation dans le masseter, grâce aux voies nerveuses de propagation, parait devoir correspondre à une période d'inoculation la plus courte possible.

c) INOCULATION INTRA-OCULAIRE.

L'inoculation par voie intra-oculaire, c'est-à-dire l'injection dans la chambre antérieure de l'oil, se montre en général une voie très fidèle et très sûre. Sans être aussi active que l'inoculation intra-cérébrale, elle reste avec la plupart des virus un mode sévère d'inoculation.

\section{d) INOCULATION INTRA-CÉRÉBRALE}

C'est Pasteur qui, après avoir constaté les résultats inconstants obtenus par inoculation sous-cutanée, eut l'idée d'inoculer directement le virus à la surface du cerveau du chien, en le plaçant dans son vrai milieu d'adaptation.

Par ce procédé, Pasteur constata que la rage éclatait cent fois sur cent. Dans la suite, l'expérience montra que les résultats étaient les mêmes, que l'inoculation soit faite sous-dure-mérienne ou intracérébrale.

En pratique, suivant Bailly (le contrôle de la vaccination antirabique des animaux. Bull. Off. Int. Epizooties, mars-avril 1950), la plupart des expérimentateurs d'aujourd'hui considèrent une inoculation de virus (de rue) dans les muscles cruraux comme une épreuve de mlême ordre que celles que les animaux sont exposés à subir dans les conditions naturelles. Il faut une immunité beaucoup plus intense pour que les animaux résistent à une introduction du virus dans la chambre antérieure. Quant à la 
vole cérébrale, elle paraît ne devoir être utilisée que pour éprouver le virus sur les témoins.

\section{III. - Nombre d'injections de vaccin et inter- valle entre chaque injection.}

Les premières vaccinations du chien ont été faites par Pasteur. Suivant sa technique, les chiens recevaient, chaque jour, par injections sous-cutanées, une émulsion de moelle desséchée de virulence croissante; le premier jour, ils étaient inoculés avec la moelle du $13^{e}$ jour, et le dernier jour, il s'agissait de la moelle du lapin extraite le jour mème. La commission de contrôle, constituée en maj 1884 . put constater que 23 chiens ainsi vaccinés etaient complètement réfractaires aux différents virus des rues. Il y avait aussi 19 témoins qui ont eu : 3 cas de rage sur 6 à la suite de morsures par chiens enragés, 6 cas sur 8 à la suite d'inoculation intra-veineuse, 5 cas sur 5 à la suite d'inoculation intra-cérébrale.

Des cette époque, Pasteur s'est posé la question de savoir s'il ne serait pas possible d'éteindre la rage ou de diminuer sa fréquence en vaccinant les chiens. Malheureusement, avec la technique pasteurienne, on se heurtait à des difficultés pratiques considérables, nombre de lapins utilisés et fréquence des injections, aussi Pasteur abandonna ce projet. Mais on ne saurait trop se rappeler que cette premiere expérimentation a démontré, indubitablement, qu'une vaccination préventive très efficace des chiens était possible avec un certain nombre d'injections.

Cette question de vaccination des chiens a été reprise dans la suite, mais, actuellement, elle n'est pas encore complètement résolue, comme en témoigne le rapport de la première session du Comité d'Experts de la Rage de l'O. M. S. (Genève, avril 1950).

Il est bien certain qu'en médecine vétérinaire, où le côté économique est primordial, il est nécessaire de réduire le plus possible le nombre d'injections donnant une immunité relative si l'on veut que la vaccination préventive des chiens entre dans le domaine pratique.

En ce qui conceme le vaccin formolé, Plantureux, qui en a été le promoteur, a constaté, dès le début de son expérimentation, que l'immunité était d'autant plus solide que l'on pratiquait un plus grand nombre d'injections et que l'on laissait entre elles un plus grand intervalle.

Ainsi avec l'émulsion $B$ au $1 / 6$ (expérimentation p. 65), il est établi que, sur 5 singes vaccinés par cinq injections, il n'y a qu'un seul mort après inoculation intra-cérébrale.

Suivant la technique que Plantureux a finalement adoptée, les chiens, quelle que soit leur taille, reçoivent $40 \mathrm{~cm}^{3}$ de vaccin, répartis en deux injec- tions sous-cutanées de $20 \mathrm{~cm}^{3}$, faites à intervalle de 3 semaines.

Dans notre première série d'expérimentations sur les chiens, la méthode de Plantureux a été strictement suivie, et les deux injections de vaccin ont été faites à intervalle de 3 semaines.

Après cette expérimentation, nous nous sommes demandés s'il ne serait pas possible de raccourcir l'intervalle entre chaque injection sans compromettre les résultats, et nous avons pris comme base l'injection hebdomadaire. En A. O.F, il faut considérer en effet, d'une part, que les propriétaires des chiens, assez insouciants, auront tendance à oublier de venir représenter l'animal 3 semaines après la première intervention, d'autre part, il faut tenir compte que les vétérinaires vaccinateurs, de par leur service, sont obligés de faire frćquomment des tournées en brousse et qu'il leur est difficile de prendre l'engagement 'd'être encore présents au poste 3 semaines après la première séance de vaccination. (Le vaccin antirabique phéniqué est utilisé chez les chiens en deux injections sous cutanées, chacune de $40 \mathrm{~cm}^{3}$ faites à 48 heures d'intervalle). L'intervalle hebdomadaire nous a paru d'autant plus intéressant à adopter qu'aux Indes Néerlandaises, la vaccination préventive des chiens est pratiquée avec du vaccin formolé injecté en trois doses hebdomadaires (L. Otten-Investigation into Rabies-Antonie Van Leeuwenhoeck, T. 13, 1947. Analysé in B. I. P., 1949, p. 274).

Les résultats que nous avons obtenus, et qui sont résumés dans le tableau page 65 prouvent que l'intervalle hebdomadaire donne toute satisfaction; par conséquent, cet intervalle peut être adopté dans la pratique courante. Mais il est certain que, si certaines contingences de la vaccination rendent plus commode l'intervalle de trois semaines, celui-ci peut être aussi choisi.

Quant au nombre d'injections, nous nous en sommes tenus à deux, suivant l'expérimentation faite maintenant sur une large échelle en Algérie.

\section{Importance de la concentration de l'émulsion vaccinogène antirabique.}

Si l'on considère que les injections $A$ ont été faites avec une émulsion au $1 / 10$ (taux de formol 6 pour 1.000 ) et les injections $B$ avec une émulsion au 1/6 (taux de formol 4 pour 1.000), il faut constater que l'émulsion $B$, soit en injections sous-cutanées, soit en injections intra-musculaires, a un pouvoir immunisant beaucoup plus élevé que l'émulsion $A$.

Ceci corrobure la notion connue que le pouvoir immunisant d'un vaccin antirabique est d'autant plus élevé que l'on injecte une plus forte quantité de matière cérébrale, c'est-à-dire, en fait, une plus grande quantité de virus. 


\section{Importance}

de la voie d'injection intra-musculaire.

Que ce soit avec l'émulsion $A$ ou avec l'émulsion $B$, le pourcentage des' animaux immunisés est beaucoup plus élevé en utilisant les injections intramusculaires au lieu des injections sous-cutanées. Et il est essentiel de noter que les cynocéphales vaccinés par voie intra-musculaire ont subi une première épreuve par inoculation intra-musculaire et une seconde par voie intra-oculaire, ce qui représente un mode d'inoculation extrêmement sévère ; les cynocéphales vaccinés par voie sous-cutanée n'ont été soumis qu'aux inoculations intra-musculaires.

Ceci vérifie aussi la notion physiologique que l'absorption par voie parentérale est beaucoup plus rapide avec des injections intra-musculaires qu'avec des injections sous-cutanées.

Il ne semble pas que cétte notion ait été prise beaucoup en considération en ce qui concerne la vaccination antirabique. Pourtant, comme notion classique, il est admis qu'en matière de rage, le traitement est une lutte de vitesse entre le virus des rues, en voie d'ascension vers le névraxe par l'intermédiaire des nerfs périphériques, et le vaccin qui, absorbé par la voie sanguine et lymphatique, doit avoir immunisé les centres nerveux avant que le virus n'y soit parvenu.

Ceci étant dit, il est important de faire remarquer qu'en matière de vaccination préventive antirabique, l'immunisation obtenue n'est jamais absolue et le pourcentage des succès n'atteint jamais $100 \%$. Bailly conclut ainsi son mémoire sur le contrôle de la vaccination antirabique des animaux : «L'épreuve d'efficacité, convenablement choisie, doit déterminer la rage chez la majorité des témoins ; on n'exige pas la survie de $100 \%$ des vaccinés, mais l'efficacité sera appréciée par la différence de mortalité entre le lot des vaccinés et celui des témoins. 》

Ainsi, au Comité d'Experts de la Rage de l'O. M. S, il a été admis qu'avec les tests d'activité sur les cobayes (Koprowski), 66 \% des animaux témoins devaient mourir de rage et $80 \%$ des animaux vaccinés devaient être protégés. Le vaccin formolé préparé par l'Institut Pasteur de Kindia remplit donc les conditions d'efficacité que l'on peut exiger d'un vaccin antirabique.

\section{Résorption du vaccin formolé.}

Comme le vaccin formolé préparé par l'Institut Pasteur de Kindia est une émulsion très concentrée de substance cérébrale, faite intentionnellement en vue d'augmenter ses propriétés vaccinantes, il faut nécessairement en tenir compte dans l'appréciation du temps concernant la résorption du vaccin : le vaccin formolé comporte une émulsion au $1 / 6$, le vaccin phéniqué une émulsion au 1/20. Et il est évident aussi qu'étant donné la concentration de l'émulsion, il $\mathrm{y}$ a lieu de pratiquer les injections dans les meilleures conditions possibles d'asepsie.

Il faut d'abord faire remarquer, suivant l'expérimentation faite; que la résorption, avec des injections intra-musculaires, est beaucoup plus rapide qu'avec des injections sous-cutanées.

$\mathrm{Si}$, dans certains cas particuliers, on veut accélérer la résorption, il suffit de pratiquer en même temps une injection d'hyaluronidase, produit biologique d'origine enzymatique qui est couramment employé en clinique humaine pour accélérer la résorption des liquides injectés par voie sous-cutanée. Par ailleurs, l'intervalle d'une semaine entre chaque injection n'est nullement impératif.

Enfin, un vétérinaire a attiré notre altention sur le fait que les injections effectuées avec une émulsion concentrée devaient être assez douloureuses, à en juger par les réactions de certains chiens. Nous avons dû répondre que la douleur, phénomène subjectif, devait être bien difficile à apprécier chez un animal.

En tout cas, nous pouvions citer une expérimentation humaine, faite tout récemment : faute d'avoir en temps voulu du vaccin phéniqué, le MédecinChef de la Formation Sanitaire de Kindia a entrepris avec du vaccin formolé, sur nosiconseils, le traitement préventif antirabique chez 10 Africains mordus par un chien reconnu enragé. Par injections sous-cutanées, ceux-ci ont accusé une petite douleur disparaissant rapidement.

Par injections intra-musculaires, ceux-ci ont été unanimes à déclarer que les piqûres ne faisaient pas plus mal que d'autres, reçues au dispensaire pour soigner diverses affections. Et il n'y a pas eu d'induration au point d'injection.

Cette expérimentation humaine doit apaiser toute crainte dans l'emploi du vaccin chez les animaux, quant aux réactions douloureuses.

(Institut Pasteur de Kindia, Guinée, A. O. F.) 